\title{
QUÃO DELIBERATIVAS SÃO DISCUSSÕES NAREDE? UM MODELO DE APREENSÃO DA DELIBERAÇÃO ONLINE
}

\author{
Rafael Cardoso Sampaio
}

\begin{abstract}
RESUMO
O presente artigo apresenta um conjunto de indicadores para a análise de conversações realizadas na internet à luz das teorias de democracia deliberativa. O modelo que se propõe é composto por um exame da estrutura de um fórum online, a avaliação dos atores envolvidos no debate, o ponderamento do contexto da discussão e pela análise da "deliberatividade" das mensagens em si, em que se toma os princípios de Habermas para a esfera pública. Finalmente, o modelo descrito de deliberação online é aplicado a mensagens retiradas do fórum online do Orçamento Participativo Digital de Belo Horizonte. A aplicação do modelo indica que a discussão apresentou bons resultados de deliberatividade, especialmente no que tange à justificação das mensagens e ao respeito pelos outros usuários. Ao fim, evidencia-se que o modelo pode ser amplamente aplicado em discussões online em diferentes plataformas ou, com certas adaptações, em outros meios discursivos, como mídias maciças ou parlamentos presenciais.
\end{abstract}

PALAVRAS-CHAVE: participação civil; democracia deliberativa; esfera pública; deliberação online.

\section{INTRODUÇÃO ${ }^{1}$}

Na Teoria Política contemporânea, o conceito de participação política civil é freqüentemente aliado a concepções e aos ideais da democracia deliberativa. Apesar de nem toda participação civil ser deliberativa, os conceitos caminham juntos em inúmeros trabalhos (COHEN \& FUNG, 2004; FUNG, 2004; VITALE, 2006). Diversos autores admitem que participação e deliberação não são conceitos idênticos, sendo que uma maior participação pode levar a um enfraquecimento da deliberação, enquanto uma melhor deliberação pode exigir uma menor participação (COHEN \& FUNG, 2004). Por outro lado, tanto participacionistas quanto deliberacionistas defendem, entres outros elementos, que as democracias liberais representativas não são accountable e responsivas o suficiente e que as eleições, como forma única de controle dos

\footnotetext{
1 Agradeço a Wilson Gomes por parte da literatura aqui utilizada; a Jamil Marques e a Rousiley Maia pelas sugestões vitais para a revisão no modelo inicial, bem como aos comentários dos pareceristas anônimos da Revista de Sociologia e Política. Pesquisa realizada com o apoio do Conselho Nacional de Desenvolvimento Científico e Tecnológico (CNPq) e da Coordenação de Aperfeiçoamento de Pessoal de Nível Superior (Capes).
}

cidadãos sobre seus representantes, não são suficientes para legitimar as decisões políticas (HABERMAS, 1997; DRYZEK, 2004; FUNG, 2004; GUTMANN \& THOMPSON, 2007).

Então, ambas teorias defendem uma participação civil maior e mais constante nas tomadas de decisões. Os cidadãos deveriam ter papéis mais efetivos nas escolhas públicas ou, ao menos, mais e melhores meios e oportunidades de enviarem demandas e necessidades aos representantes políticos. Um componente adicional refere-se à idéia de que tais inputs, no caso de não apresentarem impacto direto, sejam considerados nas tomadas de decisões (COHEN \& FUNG, 2004; VITALE, 2006).

Entretanto, os deliberacionistas afirmam que essa participação dos cidadãos deve ser qualificada, geralmente criticando políticas agregativas, como o próprio voto (DRYZEK, 2004). Em vez de uma política de poder e interesse, eles defendem uma política mais deliberativa, na qual os cidadãos consideram os problemas públicos por meio de uma racionalização conjunta, que visa a melhor forma de resolver essas questões por meio do discurso. A deliberação deve ser isenta, o máximo possível, de forças e coerções, valorizando essencialmente o poder do argumento dos participantes. Uma democracia mais 
deliberativa pode ser uma melhor opção para a solução de problemas do que o sistema representativo, porque teoricamente facilita a identificação de problemas, a colaboração em sua resolução, o teste de tais soluções e suas adequações às circunstâncias locais (HABERMAS, 1997; COHEN \& FUNG, 2004; FUNG, 2004; GUTMANN \& THOMPSON, 2007).

Outra vantagem elencada da deliberação é que ela tratar-se-ia de um processo aberto, contínuo, ou ainda, a deliberação sempre estaria aberta para uma revisão dos posicionamentos dos participantes ou para uma mudança das escolhas. Dito de outra forma, se a deliberação não alcançar os resultados mais justos, como argumentam críticos (SANDERS, 1997; VITA, 2004), o processo continuaria aberto para que os próprios participantes possam revisá-lo no futuro.

Com o crescimento do uso da internet e com a maior utilização de plataformas que valorizam a interação entre os indivíduos (como fóruns online, sítios de redes sociais e as ferramentas discursivas que passaram a acompanhar modalidades que eram monológicas, como vídeos, imagens e notícias), diversos deliberacionistas vêem a internet como um possível caminho para uma democracia que valorize mais a deliberação entre seus cidadãos. Geralmente, argumenta-se que a rede mundial de computadores mitiga alguns dos principais problemas da participação deliberativa, como a falta de tempo, o limite de espaço e a dificuldade de considerar-se um número representativo de opiniões, sendo que a internet poderia até criar novas formas de mobilização (MITRA, 2001).

Assim, diversos autores têm apostado em formas de institucionalizar a deliberação democrática (FUNG, 2004; WARREN, 2007), sendo as ferramentas digitais online uma possível maneira de realizar-se ou incrementar tais programas (COLEMAN \& GØTZE, 2001). Outra linha de pesquisa, aquela que se deseja desenvolver, tem extraído indicadores de qualificação de deliberações e aplicado em diversos debates realizados na internet. Essa perspectiva é geralmente denominada como "deliberação online" (online deliberation) ou "deliberação na rede" (web deliberation ou e-deliberation).

Apesar de existirem inúmeros estudos acerca da deliberação online, que exibem diferentes formatos e objetivos distintos, identifica-se quatro ênfases de tais pesquisas. O primeiro conjunto de trabalhos compara deliberações online com as presenciais, buscando-se geralmente comprovar que as discussões virtuais podem apresentar as mesmas vantagens das offline. Em alguma medida, tais estudos buscam afirmar a importância do próprio campo de estudos de deliberação online (GASTIL, 2000; HAMLETT, 2002; MIN, 2007; MONNOYER-SMITH, 2012).

O segundo grupo de pesquisas parte da premissa que a internet é um componente da esfera pública ${ }^{2}$. Pressupõe-se que a internet não seja um meio isolado, logo, grande parte do que é discutido online também pode ser discutido em diversos outros públicos ou em outras mídias. Ou, em uma segunda vertente, o que é discutido online pode ganhar repercussão na esfera pública por meio da aparição em mídias de massa tradicionais, como $\mathrm{TV}$, rádio e impresso. Logo, a análise da qualidade das discussões online é parte da avaliação das discussões da própria esfera pública, logo as apreensões acontecem em fóruns online diversos (WILHELM, 2000; GRAHAM \& WITSCHGE, 2003; PAPACHARISSI, 2004; DAVIS, 2005; JANSSEN \& KIES, 2005).

O terceiro conjunto de estudos geralmente analisa a deliberação em programas participativodeliberativos ou em fóruns online hospedados em sítios institucionais. Sendo consultivos ou empowered, geralmente tais processos tornam disponíveis fóruns online, chats e ferramentas digitais diversas para a discussão dos cidadãos ou mesmo para o debate entre representantes e cidadãos. Nesses casos, geralmente, a apreensão da deliberação online visa a verificar se o processo participativo conseguiu abrigar uma deliberação qualificada, buscando-se compreender se os motivos para tais resultados encontram-se no formato do programa, nas ferramentas digitais disponibilizadas ou nos atores envolvidos (DAHLBERG, 2001; JENSEN, 2003; JANKOWSKI \& VAN OS, 2004; WRIGHT \& STREET, 2007; LAZER, NEBLO \& ESTERLING, 2012).

O quarto agrupamento de pesquisas busca investigar a importância do design e da estrutura das ferramentas digitais. Tais estudos buscam demonstrar como tais aspectos podem influenciar

\footnotetext{
2 Grande parte dos autores faz uso do conceito de "esfera pública" de Habermas (1984; 1997).
} 
diretamente nos resultados da deliberação online. Assim, são analisadas características diversas, como necessidade de identificação, moderação, controle da discussão e características técnicas dos softwares (como funciona a resposta, baseada em texto ou voz, possibilidade de trocar mensagens privadas ou não, capacidade de troca de arquivos e informações etc.) (NOVECK, 2003; SALTER, 2004; JANSSEN \& KIES, 2005; WRIGHT \& STREET, 2007).

Entretanto, mesmo sendo uma área de pesquisa bastante desenvolvida, especialmente, nos Estados Unidos e na Europa, a idéia de deliberação online ainda é rara nos estudos brasileiros. Com exceção a alguns poucos trabalhos que buscaram analisar ferramentas digitais sob uma perspectiva deliberacionista (MARQUES \& MIOLA, 2007; BRAGATTO, 2008) e estudos raros que efetivamente analisaram deliberação online ${ }^{3}$ (MIOLA, 2009; DANTAS \& SAMPAIO, 2010; MARQUES, 2010; SAMPAIO \& BARROS, 2010; SAMPAIO, MAIA \& MARQUES, 2010; ALVES, 2011; IASULAITIS, 2011; MALVA, 2011; MENDONÇA, PEREIRA, 2011), o campo é praticamente intocado no Brasil.

De tal maneira, esse artigo busca colaborar com tal área de estudos que ainda encontra-se incipiente no campo nacional por meio da apresentação de um modelo de apreensão da deliberação online. Nesse artigo, objetiva-se apresentar um modelo mais completo que possa ser aplicado, com poucas adaptações, ao estudo do perfil discursivo de qualquer conversação online.

Assim, o artigo está dividido em três partes. Na primeira, é exposto o modelo de apreensão da deliberação online, que envolve análises do contexto dos atores envolvidos, das ferramentas digitais utilizadas e da deliberatividade das mensagens. Na segunda seção do artigo, é realizada uma breve descrição do Orçamento Participativo Digital (OPD) $)^{4}$, objeto no qual o modelo foi

3 Foi realizada uma pesquisa no sítio do Scielo e no Google Acadêmico pelas palavras-chave "deliberação+online". A lista aqui apresentada não pretende ser exaustiva, mas apenas destacar que se trata de uma área que ainda não tem recebido atenção.

4 O OPD é um pertinente caso para a aplicação do modelo de deliberação online. Além de ser uma das únicas iniciativas brasileiras a permitir o cidadão realizar uma efetiva decisão política pela internet (e com uma participação em aplicado. Na última parte do artigo, são apresentados os resultados da deliberação online e são ponderados os limites e a possibilidades de aplicação do modelo em outros ambientes.

\section{UM MODELO DE DELIBERAÇÃO ONLINE}

O modelo a seguir foi desenvolvido a partir de reflexões extraídas de outras pesquisas de deliberação online, nas quais foram destacados os indicadores analíticos mais consistentes e pertinentes.

O principal autor de referência com relação aos estudos de deliberação online a ser utilizado será Lincoln Dahlberg (2001; 2004a). Trata-se de um dos primeiros pesquisadores a traduzir a teoria de Habermas em indicadores analíticos consistentes para serem aplicados à internet. Dahlberg destaca as diversas características atribuídas por Habermas (1984) à esfera pública ideal e transforma-as em indicadores qualitativos para as conversações. De maneira simples, podese dizer que quanto maior a presença de tais indicadores, maior será a deliberatividade, ou ainda, melhor será a qualidade da discussão em relação aos aspectos valorizados pela teoria deliberativa.

Contudo, os indicadores propostos por Dahlberg restringem-se apenas ao processo discursivo em si, ignorando questões importantes, como o contexto sócio-cultural na qual a deliberação acontece, o posicionamento dos atores envolvidos e o design ou a estrutura das ferramentas digitais de conversação. Nesse sentido, as proposições de Janssen e Kies (2005) e Jensen (2003) serão complementares ao modelo de Dahlberg.

\section{II.1. Análise estrutural do fórum}

Janssen e Kies (2005) sugerem duas análises estruturais do contexto no qual o fórum online está inserido antes da própria análise das mensagens. A primeira refere-se à estrutura comunicativa do fórum, enfatizando-se aspectos como acesso, liberdade de postar mensagens, impacto político etc. A segunda análise refere-se

torno de $10 \%$ do eleitorado), o fórum online do OPD também se destaca por estar no mesmo sítio da ferramenta digital de votação. Como demonstrado em outro trabalho (SAMPAIO, 2010), o fórum acabou sendo uma plataforma de mobilização, reivindicação, discussão e mesmo deliberação, sendo um caso único de participação online do cidadão brasileiro. 
à cultura política e à ideologia dos participantes e do ator político que hospeda ${ }^{5} \mathrm{o}$ fórum.

\section{II.1.1. Estrutura comunicativa}

$\mathrm{Na}$ estrutura comunicativa, Janssen e Kies (idem) propõem que sejam averiguados cinco questões e os motivos para tais escolhas. Primeiramente, deve ser avaliada a questão do anonimato. Segundo os autores, o anonimato pode tanto facilitar a discussão por minimizar as diferenças sócio-econômicas entre os participantes quanto diminuir a responsabilidade em relação a ela. Porém, os autores defendem que há indicações de que conversas online com indivíduos identificados tendem a fluir melhor. De tal forma, sugere-se que todas as mensagens analisadas no fórum discursivo em questão sejam classificadas como "anônimas" ou como "identificadas".

Em segundo lugar, Janssen e Kies (idem) propõem que seja analisada a "abertura" e a "liberdade de discursos". Diversos tipos de fórum costumam exigir cadastro ou, mesmo, restringem o acesso a certas pessoas ou ainda limitam o número de postagens por tempo, visando impedir que as conversas sejam dominadas por poucos indivíduos, o que é defendido por certos autores como necessário a uma igualdade discursiva (WILHELM, 2000; DAVIS, 2005).

Em terceiro lugar, Janssen e Kies (2005) sugerem a avaliação da atuação do ator político que hospeda a discussão. Ou, em outras palavras, discutem se a "agenda da discussão" pode ser feita pelos participantes, se é centralizada pelos organizadores ou por temas e, em quarto, se há "moderação". O controle da agenda é um limitante não apenas aos assuntos, mas à discussão em si $\mathrm{e}$, ocasionalmente, pode influenciar negativamente a deliberação.

Como na questão do anonimato, há certa controvérsia em relação à moderação. Há muita resistência ao controle e à censura na internet. Muitos participantes defendem que as discussões devem ser totalmente abertas e que os temas indesejáveis serão naturalmente combatidos pelos próprios usuários da rede ${ }^{6}$. Outros pesquisadores

\footnotetext{
${ }^{5}$ No sentido técnico (host), ou seja, o endereço eletrônico (sítio) no qual o fórum localiza-se.

${ }^{6}$ Ver Gomes (2002) para uma apresentação dos discursos favoráveis à liberdade na internet.
}

(JENSEN, 2003; PAPACHARISSI, 2004; DAVIS, 2005; WRIGHT \& STREET, 2007) defendem que a moderação tende a contribuir para o debate, uma vez que organiza as discussões e inibe situações de conflito, o que também é defendido por Janssen e Kies (2005). Porém os autores afirmam (idem) que o moderador também pode atuar como um promotor da deliberação, dando voz àqueles que menos participam, buscando informações e mantendo o debate ativo.

Finalmente, Janssen e Kies propõem a análise do fórum como um "espaço público forte" ou "fraco". Em sua definição, o espaço será forte quando os participantes acharem que sua participação será lida e considerada por outros usuários ou que possa ter resultados políticos concretos. Pelo contrário, ele será fraco se os participantes não acreditarem que sua participação conta e que nenhum resultado político irá advir de seu debate online (idem). A literatura aponta que os espaços públicos fortes tendem a ser mais deliberativos, pois as pessoas justificam mais suas posições (FUNG, 2004).

\section{II.1.2. Cultura política e ideologia dos partici- pantes}

Na outra análise estrutural sugerida por Janssen e Kies (2005), é avaliada a cultura política e a ideologia dos participantes e do ator político a hospedar a discussão. Essa estrutura busca avaliar diversos aspectos que podem influenciar a deliberação, como "diferenças culturais entre regiões" (i), o "tipo de ator político a hospedar o debate" (ii) e a "ideologia das pessoas" que são atraídas por esse ator político (iii). Por serem importantes para a avaliação de deliberação e também de participação, os autores concluem que são necessárias pesquisas de opinião (surveys) ou entrevistas em profundidade com os usuários para apreender tais dados (idem).

O último aspecto da análise estrutural sugerido pelos autores é o "tópico de debate" (iv), que pode influenciar os resultados da deliberação e as pessoas que dele participam. Por exemplo, se o assunto em pauta for "violência doméstica", há maior probabilidade das mulheres estarem mais presentes, assim como se a pauta for "regras de aposentadoria", o número de adultos tende a ser maior que o de jovens.

Em resumo, pode-se afirmar que as duas análises estruturais propostas por Janssen e Kies 
(idem) dividem-se conforme a Tabela 1, abaixo. É preciso frisar que elas estão diretamente relacionadas ao contexto no qual o fórum online está inserido. O objetivo de tal análise é entender os diversos fatores "externos" que podem moldar a deliberação.

TABELA 1 - ANÁLISE ESTRUTURAL DO FÓRUM ONLINE

\begin{tabular}{|l|c|}
\hline \multicolumn{1}{|c|}{ ESTRUTURA COMUNICATIVA } & CULTURA POLÍTICA E IDEOLOGIA \\
\hline 1. Identificação & I. Diferenças culturais entre regiões \\
2. Abertura e liberdade & II. Tipo do ator político a hospedar o debate \\
3. Agenda da discussão & III. Ideologia dos participantes \\
4. Moderação & IV. Tópico de debate \\
5. Espaço público forte ou fraco & \\
\hline
\end{tabular}

FONTE: o autor, a partir de Janssen e Kies (2005).

\section{II.1.3. Design e conteúdo}

A estrutura comunicativa proposta por Janssen e Kies (idem) já toca em alguns aspectos do design do fórum online, mas não de maneira suficiente. Os formatos das ferramentas digitais de participação são variáveis importantes a serem consideradas, pois influenciam diretamente o resultado final da participação dos cidadãos (GRÖNLUND, 2003; WRIGHT \& STREET, 2007; FERBER, FOLTZ \& PUGLIESE, 2007).

Há duas maneiras principais de analisar-se o design da ferramenta digital. A primeira, mais complexa, compreende a utilização de fichas de análise do sítio ${ }^{7}$. O pesquisador, normalmente, elenca as principais características que determinadas ferramentas ou sítios podem dispor. Se, por exemplo, avaliam-se as ferramentas deliberativas de um sítio, a ficha pode conter itens que irão averiguar a presença de um fórum online, de um chat, uma ferramenta de postar comentários ou utilização de redes sociais online. Dentro de cada uma, a ficha pode conter itens diversos, como a possibilidade de responder-se diretamente a outra pessoa, de enviar-lhe mensagens privadas, o fato de um e-mail gerar um protocolo de atendimento ou não etc.

A segunda forma de avaliação dá-se por meio da pesquisa qualitativa. Para tanto o pesquisador analisa o sítio de maneira geral e depois interpreta

7 Para apresentações diversas de tais fichas de análise ver Marques e Miola (2007), Bragatto (2008) e Silva et alii (2009). o nível de sofisticação apresentado pelas ferramentas. Apesar de ser um método mais subjetivo, ele pode levar a resultados menos restritos. Em estudo anterior (SAMPAIO, 2010), optou-se pela análise qualitativa, que se concentrou nos quesitos "funcionalidade" e "conteúdo". A funcionalidade está diretamente relacionada à facilidade de navegação e, principalmente, de usarem-se as ferramentas de participação e deliberação. Um sítio mal organizado, ou que dificulte achar as ferramentas de participação, pode inibir a ação dos cidadãos; uma ferramenta que não permita responder diretamente a outro usuário pode dificultar a deliberação, entre outras possibilidades.

Em relação ao conteúdo, tenta-se apreender a dificuldade de aquisição de informações a respeito das ferramentas tecnológicas e dos processos participativos. O conteúdo deve ser claro, conciso e permitir tanto uma leitura rápida quanto uma pesquisa aprofundada sobre o assunto, considerando, assim, os diferentes níveis de informação dos usuários.

\section{II.2. Análise das falas}

Antes de apresentar o modelo proposto por Dahlberg (2004a), é preciso considerar questões importantes a respeito das mensagens. Ao tratarse de fóruns online, usualmente, há uma divisão por tópicos, que podem ser iniciados pelos usuários ou, em determinados casos, pelo ator político que hospeda o debate online. Há dois critérios que não são considerados por Dahlberg, mas que podem alterar os resultados.

O primeiro e mais importante é se a mensagem 
é "relevante" ou não. As mensagens irrelevantes geralmente não tratam do tópico discutido (offtopic), são propagandas (spam) ou ainda sem demandas. Steenbergen et alii (2003), por sua vez, sugerem a seleção das mensagens com a presença de demandas; isto é, eles tratam como irrelevantes as mensagens que não tenham perguntas, respostas ao tópico, sugestões ou simplesmente demandas em relação a outros atores ou ao assunto. Diversos autores (GRAHAM \& WITSCHGE, 2003; JENSEN, 2003; MIOLA, 2009) classificam as mensagens irrelevantes como totalmente à parte do restante da avaliação da deliberação. Outros pesquisadores (WILHELM, 2000; DAVIS, 2005) simplesmente consideram-nas mensagens pouco deliberativas e as classificam normalmente com as outras. Exemplos de mensagens sem demanda seriam: "Obra 4. Felipe (13.nov.2008, 2h19min3s): Passou da hora! E vai ganhar!” (OPD, 2008). "Obra 4. Anselmo José Dias (19.nov.2008, 10h46min19s): Ótimo. Mais do que necessária!” (idem).

Em nossa aplicação, foi realizada uma seleção do corpus que já desconsidera as postagens irrelevantes, entretanto a porcentagem de mensagens irrelevantes é um dado importante por si. Um alto valor de mensagens irrelevantes tende a indicar um baixo comprometimento com a discussão e, provavelmente, baixa deliberatividade, sendo o inverso também verdadeiro.

O segundo critério que deve ser considerado, antes da aplicação do modelo de deliberação propriamente dita, é se a mensagem é "inicial" ou se é uma "resposta" (GRAHAM \& WITSCHGE, 2003). Especialmente, se a postagem for classificada como inicial, deve haver um cuidado extra pelo pesquisador. Ela, por exemplo, não deveria ser contada nos critérios de reciprocidade e reflexividade, afinal ela inicia a própria discussão e não pode responder a si mesma. Por outro lado, diversos fóruns online dispõem de inúmeras divisões. Um fórum que trata do orçamento participativo digital, por exemplo, poderia estar dentro de diversas divisões, como: política; participação popular; participação online e OPD. Assim, alguns pesquisadores podem replicar que mesmo a mensagem inicial pode estar respondendo ou não a esse tema geral proposto pela organização do fórum online. Alguns fóruns, como sítios de jornais e blogs, podem iniciar o tópico de discussão por meio de uma matéria jornalística ou de uma sugestão de discussão proposta por algum moderador. Nesses casos, a mensagem inicial deve ser considerada normalmente.

Abaixo é apresentado o modelo de apreensão da deliberatividade. Algumas mensagens extraídas do fórum online do OPD são dispostas para se facilitar a compreensão dos indicadores.

\section{II.2.1. Tematização e críticas racionais de} pretensões de validade

O primeiro critério é chamado de "tematização e críticas racionais de pretensões de validade" ("Thematization and reasoned critique of problematic validity claims") (DAHLBERG, 2004b, p. 13). O objetivo é entender se as posições estão sendo apresentadas e se são debatidas criticamente. As posições dos participantes, no ideal deliberacionista, devem ser apoiadas por razões. Assim, são avaliadas duas dimensões.

Inicialmente, é avaliada a "reciprocidade" (1), ou seja, se as pessoas estão lendo as mensagens e respondendo. É um nível mais superficial, que não exige profundidade argumentativa da réplica, mas apenas o ato de responder a outro usuário ou ao assunto em pauta. Por exemplo: "Obra 4. Carlos BH (14.nov.2008, 12h59min50s): Comentários iguais ao cidadao Eberth mostram o quanto a populacao desconhece a dinamica de uma metropole e me decepcionam quanto a postura agressiva e radical. Onde existem carroes existem tambem onibus, carrinho, fusca, etc.... e muita gente indo e vindo [sic]" (OPD, 2008).

Em segundo lugar, as mensagens que não apresentarem respostas são classificadas como "monológicas" (2). Por exemplo: "Obra 4. PAULO CAMPOS (13.nov.2008, 12h51min21s): É uma intervenção necessária e tardia!!! Bom que saia em 2011 mas já era para estar acontecendo!!! Demorô [sic]" (idem).

Entretanto, é necessário cautela ao considerarse um fórum como pouco deliberativo pela ausência de reciprocidade entre os usuários. Percebeu-se, ao realizar a aplicação de tais indicadores, que há certa desconsideração da multiplicidade de espaços discursivos da internet e que os usuários não estão presos ao fórum

\footnotetext{
8 Enumeraremos os critérios utilizados no modelo aqui apresentado, escolhidas a partir dos vários autores considerados, com números indo-arábicos entre parêntesis.
} 
analisado. Dito de outra forma, os participantes podem responder ou replicar a discussão em outros sítios ou sistemas online, como sítios de redes sociais ou mesmo outros fóruns, que estejam mais próximos aos seus hábitos de consumo online. Assim, surveys com os usuários podem ser úteis para uma melhor apreensão de tal critério.

Em terceiro lugar, é avaliada a justificação, ou seja, se as pessoas estão apresentando razões para apoiar seus argumentos. Jensen (2003) apresenta três possibilidades de justificação (ou validação) que parecem coerentes. A "justificação externa" (3), é aquela em que o usuário utiliza-se de fontes externas para manter seu argumento, sejam fatos (exemplos de acontecimentos), dados (relatórios), notícias etc. Por exemplo: "Obra 4. Juliana (19.nov.2008, 10h31min46s): Considero que o Paulo trouxe uma questão importante para refletirmos, não se trata apenas de beneficiar a população de Nova Lima (que merece sim, vias de acesso melhores) ou de Belo Horizonte, o que está em jogo é que essas obras serão feitas em detrimento das outras e nesse ponto, é muito claro que a região do Belvedere já é muito privilegiada (boa infraestrutura, avenidas largas, calçamentos etc) e que portanto os recursos deveriam ser aplicados nos bairros onde a carência por melhores condições de tráfego é maior, onde a infraestrutura é muitas vezes pior da que já existe hoje na região do BH Shopping. Belvedere pode esperar e pode conseguir recursos de outras fontes para a realização dessa obra [sic]" (OPD, 2008).

Em quarto, a "justificação interna" (4) é baseada no próprio ponto de vista do usuário, que utiliza explicitamente seus padrões, valores e histórico pessoal (testemunho) para apoiar seu argumento. Por exemplo: "Obra 5. ALEX (24.nov.2008, 5h3min22s) ficar mais de 40 minutos parado 'todas as manhãs' no trecho do bairro dom bosco, até a praça são vicente, já é motivo para não se ter 'eleição' para qual obra realizar... esta obra é 'prioritária' para todos que moram nesta região... ou seja: todos que moram abaixo do anel - região noroeste (400.000 pessoas -20.000 carros) diários, são 'obrigados' a passar pela única pista de acesso a praça são vicente... abaixo do viaduto do anel rodoviário (av. ivaí - av. abílio machado)... é uma vergonha... não existem obras neste região... o acesso é c a ó t i c o !!! [sic]" (idem).

Finalmente, Jensen afirma que é possível ter uma alegação, ou seja, a pessoa afirma sua posição, mas não apresenta alguma justificativa ou algum fato, o que denominaremos "posição" (5). Por exemplo: "Obra 4. Leonardo (12.nov.2008, 4h57s): A obra vai desafogar o trãnsito no local que está muito ruim!!! Um abraço a todos os participantes e parabéns pelo OP Digital [sic]" (idem).

\section{II.2.2. Reflexividade}

No segundo critério de Dahlberg (2004a), temos a "reflexividade", na qual os participantes devem examinar seus valores, pensamentos e interesses em comparação com o contexto social. Em outras palavras, a pessoa deve estar disposta a avaliar a posição dos outros e até revisar a sua posição inicial se persuadida pela força de outros argumentos.

Novamente, Jensen (2003) oferece uma subdivisão que pode facilitar a apreensão do indicador. A reflexividade pode ser avaliada de três formas. Em primeiro lugar, existe "persuasão" (6) quando há sinais explícitos de que um usuário sente-se persuadido pela argumentação de outro participante ou pela discussão no geral, por exemplo: "Obra 5. Vinícius de Magalhães (24.nov.2008, 5h55min13s): A obra 5 se faz muito necessário visto os seguintes fatores: A região noroeste é a maior em população; A travessia pelo $o$ anel funciona como gargalo causando os congestionamentos que enfrentamos diariamente nos dois sentidos; Além dos congestionamentos que nós da região noroeste convivemos existe engarrafamentos frequentes também no anel rodoviário, nessa mesma altura devido a retornos, e a obra também melhoraria esse aspecto; E por último gostaria de reforçar que quem mais precisa de melhor acesso somos nós, porque nossa região há muito não sofre melhorias de infra-estrutura, ao contrário da região sul e central que é bem melhor assistida pela prefeitura. Vamos nós mobilizar por essa causa, essa é nossa chance [sic]" (OPD, 2008).

Em segundo lugar, existe "progresso" (7) quando um usuário reflete sobre outra postagem, responde com novos argumentos ou informações ou, mesmo, tenta criar uma síntese dos argumentos. Por exemplo: "Obra 4. Alessandra (13.nov.2008, 11h23min25s): [...] Concordo com o Pedro, temos que pensar no trânsito da região metropolitana como um todo: a Nossa Senhora do Carmo, Raja, BR e o Anel sofrem com o afunilamento ao redor do trevo do BH Shopping (onde o trânsito chega a ser restrito a UMA pista), 
e são muitos os cidadãos prejudicados $[s i c]$ " (idem).

Em terceiro, há "radicalização" (8) quando o usuário reage negativamente à outra postagem $\mathrm{e}$ radicaliza seu ponto de vista anterior, não estando aberto a outras possibilidades. Por exemplo: "Obra 4. Hélio (4.dez.2008, 5h12min8s): Discordo totalmente da opinião do Paulo. Ele está pensando em benefício próprio e não no bem comum da cidade. Esta Obra vai beneficar toda a região, inclusive uma região que está em constante expansão que é o Buritis [sic]" (idem).

Defende-se que uma mensagem só poderia ser considerada como reflexiva se ela também apresentar reciprocidade, apesar de Janssen e Kies (2005) não explicitarem tal minúcia. Obviamente, nem todos os usuários precisam fazer referência ao assunto para responderem ao mesmo, entretanto é preciso reconhecer as limitações da metodologia do estudo de deliberação online e analisar apenas o que está explícito ou claramente implícito. Acredita-se que, ao não aplicar essa restrição, a análise pode gerar resultados incongruentes nos quais a reciprocidade é baixa, mas a reflexividade é alta (MIOLA, 2009) ou em que a reflexividade é superior à reciprocidade (JENSEN, 2003) ${ }^{9}$.

\section{II.2.3. Ideal role taking}

O terceiro critério de Dahlberg (2004a) é o "ideal role taking", ou "tomar o lugar do outro". Para tanto, é preciso respeito para escutar e dar a devida atenção às colaborações dos outros participantes. É necessário, também, que o debate seja contínuo; que não termine abruptamente. Foi mantida a ordem sugerida pelo autor, mas, em nossa avaliação, o ideal role taking é praticamente o primeiro pré-requisito de uma deliberação de qualidade. Antes de serem capazes de responder (reciprocidade), de refletir sobre a questão e estarem dispostos a mudarem suas opiniões (reflexividade), os debatedores devem estar dispostos a ouvir uns aos outros de maneira respeitosa e, também, a dar prosseguimento ao

9 Em tais análises, a categoria que rotulamos como "reflexividade" foi considerada "reciprocidade", mas com objetivo idêntico ao nosso. Já o indicador que classificamos como "reciprocidade", é considerada "dialogicidade" pelos dois autores; entretanto, as categorias têm as mesmas funções nos três textos. debate até que se alcance um resultado mais aceitável pelos envolvidos (ideal role taking).

Em relação à escuta respeitosa, Dahlberg (idem) sugere que seja avaliada a ausência de respeito. Conforme Janssen e Kies (2005), a possibilidade de avaliação de respeito de Steenbergen et alii (2003) é possivelmente a melhor saída. Em tal análise, novamente há três divisões. O "respeito implícito", - (9) acontece quando não há posições negativas, mas também não há positivas. O "respeito explícito" (10), quando há pelo menos uma posição positiva explícita sobre grupos, independentemente da presença de posições negativas. E, finalmente, as mensagens sem respeito.

No caso de mensagens respeitosas, acreditase que a definição de Janssen e Kies não seja forte o suficiente. Foi perceptível que a simples ausência de posições negativas e positivas permite à imensa maioria das mensagens serem classificadas como "respeito implícito", e isso não necessariamente reflete seus conteúdos. De tal forma, consideramos que as mensagens precisam fazer referências a outros grupos ou indivíduos para poderem ser classificadas como formas de respeito implícito ou respeito explícito.

O respeito implícito, em nossa perspectiva, acontece quando há referências, menções a tais grupos de pessoas, mas não há posições favoráveis ou contrárias ao grupo. Ou seja, há respeito porque o falante considera a visão de outro indivíduo ou coletivo, mas não o faz de maneira explícita, como no exemplo a seguir: "Obra 5. Luiz (25.nov.2008, 6h6min54s): Concordo totalmente com a conclusão da obra, porém tenho uma crítica, pela praça São Vicente também passam moradores de Contagem, e como os votos para o orçamento participativo somente são validos para os moradores de $\mathrm{BH}$ ficaremos prejudicados pois, $\mathrm{o}$ numero de moradores de Contagem é muito grande e iria render muitos votos para esta obra. Sugiro que a votação deveria ser aberta a todos que utilizam a rodovia e não somente aos moradores de BH. Atenciosamente, ADM. Luiz Carlos Carvalho [sic]" (ODP, 2008).

$\mathrm{Na}$ mensagem acima, é possível ver que o usuário claramente está preocupado com os moradores da cidade de Contagem (Região Metropolitana de Belo Horizonte), que serão afetados por uma das obras, mas que não poderão votar, já que o OPD era restrito aos eleitores de 
Belo Horizonte. Todavia, ele não explicita exatamente por que é importante considerar tais moradores. Logo, há uma forma de respeito, porém implícita.

Considerou-se, por outro lado, que o respeito só pode ser classificado como explícito se há um claro posicionamento positivo com relação aos grupos tratados pelo falante. Geralmente, isso pode ser percebido quando o usuário faz referências a valores universais, como igualdade, direitos, dignidade humana e afim, como exemplifica a fala a seguir: "Obra 5. Cândido (24.nov.2008, $11 \mathrm{~h} 27 \mathrm{~min} 14 \mathrm{~s})$ : O problema que a MAIORIA das pessoas AFETADAS pelo transito na praça são vicente é residente em contagem o que afeta diretamente na votação, essas pessoas deveriam ter o direito de votar!!!!!!! [sic]" (idem).

O objetivo da fala de Cândido é bastante similar ao da mensagem do Luiz, acima apresentada. Por outro lado, Cândido faz apelos a valores fortes, de maneira explícita. Por exemplo, afirma que os moradores de Contagem são afetados, então devem ter o "direito" de votar, ou seja, há um apelo a direitos, à autonomia e à igualdade entre os cidadãos.

Em relação à ausência de respeito, defende-se que o trabalho de Papacharissi (2004) seja adequado para complementar a análise. A autora distingue entre mensagens rudes e incivis. Dessa maneira, também haveria duas formas de ausência de respeito. A mensagem "sem respeito: rude" (11), isto é, aquela em que há ofensas, ironias, ataques pessoais etc, mas que não atacam valores democráticos e "sem respeito: incivil" (12), na qual existem discursos de preconceito, racismo, ódio ou ataques contra princípios democráticos. Vide o exemplo: "Obra 4. Leone (27.nov.2008, 4h30min25s): O cidadão Mateus está enganado quando diz que a Região Sul é para onde cresce BH. Na verdade, a região Sul é para onde cresce o percentual de moradores milionários das cidades de BH e Nova Lima. O resto da população, a massa, faz crescer as regiões Noroeste e a região da Linha Verde na capital. Ele está certo em defender a região onde mora, citando Pátio Savassi e arredores BURGUESES, pois deve ser um filhinho de papai ou algum empresário da nossa elite. Eu o aconselho a passar na região da obra 05, no bairro da periferia chamado Alípio de Melo, num horário de pico, para conhecer melhor a realidade da cidade onde vive. Pelo que parece, ele só conhece a elite dos bares, restaurantes, boates e condomínios de luxo [sic]" (OPD, 2008).

A mensagem acima é uma das mais ofensivas de todas as conversações analisadas no OPD, entretanto, ela ainda é classificada como rude e não como incivil. Apesar das diversas formas de desrespeito, o falante não chega a realizar um discurso do ódio, ele não desfere um ataque contra valores democráticos ou contra um grupo. Apesar de ser forte e poder causar novas brigas, a mensagem de Leone também tem argumentos e sentido claro: "a região que você defende é a mais rica e menos necessitada da obra. A minha região, mais pobre, precisa mais de tal realização" (idem).

O segundo aspecto do critério ideal role taking é a continuidade das mensagens. Propõe-se que seja aferida a média de mensagens por dia (número total de mensagens sobre dias de debate) e que se compare tal média com o número de mensagens por dia. Essa comparação permite examinar se há irregularidades nos fluxos de mensagens, se houve dias de vários debates ou dias de descaso no que concerne à quantidade de mensagens postadas no fórum. Essa mensuração não permite fazer correlações fortes, mas pode ajudar os pesquisadores a compreender os elementos que estão alimentando (ou minando) a discussão.

Abandonou-se a idéia de avaliar-se o número de caracteres das mensagens (JENSEN, 2003; JANSSEN \& KIES, 2005), pois é um critério pouco valioso e muito questionável. Se somarmos os caracteres de todas as mensagens e dividirmos pelo número de postagens, iremos obter a média que as mensagens deveriam ter. Todavia é plenamente possível fazer um excelente argumento racional em poucas palavras e é possível fazer um enorme texto com poucas justificativas. Em nossa visão, isso pouco ou nada contribui para a continuidade de um diálogo.

\section{II.2.4. Sinceridade}

O quarto critério de Dahlberg é a "sinceridade". Seguindo a idéia de ação comunicativa habermasiana, o autor defende que os participantes deveriam ser sinceros em suas opiniões e evitar a ação estratégica para alcançar vantagens. Segundo Janssen e Kies (2005) pela dificuldade de apreender-se a sinceridade, geralmente é analisada a sua ausência, especialmente quando há incongruência na participação de determinados usuários. 
Assim como Steenbergen et alii (2003), acredita-se que a sinceridade seja um critério complexo demais para ser analisado unicamente pelas palavras. Qualquer tentativa de apreendê-lo pode tornar-se excessivamente subjetiva por parte do pesquisador. De tal maneira, sugere-se que o pesquisador não adote tal critério na avaliação geral da deliberação online. Warren (2007) também afirma que a melhor forma de avaliar-se a deliberação não está em concentrar-se nas intenções comunicativas iniciais dos participantes, mas sim na avaliação dos resultados da comunicação. Adotando essa perspectiva, a sinceridade dos indivíduos na deliberação não é um pré-requisito para uma deliberação de qualidade.

\section{II.2.5. Inclusão e igualdade discursiva}

O quinto critério de Dahlberg (2004a) é a "inclusão e igualdade discursiva". O debate deve ser aberto para todos os concernidos e todos os participantes devem ter oportunidade igual de manifestar-se. Uma parte desse critério já é analisada na estrutura do fórum, quando se avalia determinas questões, como liberdade e abertura de discussões e o controle da agenda temática.

Assim, no quesito inclusão e igualdade discursiva propomos que os pesquisadores analisem, principalmente, a idéia de exclusão digital, apresentando dados a respeito do número de pessoas com acesso à internet no Brasil ${ }^{10}$ ou mesmo dados específicos da região a ser analisada, especialmente, quando se tratar de regiões com altos índices de usuários (Sul e Sudeste) ou baixos índices (Norte e Nordeste) em relação à média nacional. O objetivo desse indicador não é realizar uma análise complexa da exclusão digital, que é influenciada por diversos fatores, mas evidenciar que ela deve ser considerada ao realizarem-se programas participativos online.

\footnotetext{
10 Há diversos estudos dessa natureza, como a Pesquisa Nacional de Amostra por Domicílio (PNAD) do Instituto Brasileiro de Geografia e Estatística (IBGE), o Ibope e o Datafolha. Em nossa análise do OPD (SAMPAIO, 2010), fizemos uso dos dados da pesquisa TIC, realizada pelo Centro de Estudos sobre as Tecnologias da Informação e da Comunicação (Cetic), uma pesquisa basicamente centrada em internet e que apresenta as diferenças entre as regiões brasileiras. Cf. Cetic (2012).
}

Posteriormente, ainda no indicador "igualdade discursiva", deve-se analisar se houve um domínio da discussão por poucos usuários, o que pode inibir a participação de outros cidadãos. Apesar de tal situação ser mais rara na rede, uma vez que vários indivíduos podem pronunciar-se ao mesmo tempo, certos grupos de usuários podem, por exemplo, ignorar as mensagens de outros participantes.

Todavia, enfatiza-se necessidade de analisar, justamente, o efeito contrário, ou seja, quando as pessoas postam apenas uma vez ("one-timer effect"). Segundo Jensen (2003), essa situação dificulta a complexificação do debate, principalmente se avaliado do ponto de vista de critérios como reciprocidade e reflexividade. Assim, além de classificar cada postagem como anônima ou identificada, sugere-se que sejam classificadas pelo nome do usuário que a postou, o que permitirá um acompanhamento do número de mensagens por indivíduo.

\section{II.2.1.6. Autonomia do Estado e do poder econômico}

O sexto e último critério de Dahlberg (2004a) é a "autonomia do Estado e do poder econômico". A deliberação deve ser direcionada por motivos, pelas necessidades públicas dos cidadãos e não pelo dinheiro ou pelo poder administrativo. Tal critério precisa ser analisado com cuidado extra. Jensen (2003), por exemplo, evidenciou que um fórum online mantido por uma instituição política alcançou resultados deliberativos superiores aos de um fórum sustentado pela esfera civil. Logo, nem sempre a autonomia do Estado, como sugere o caso, será sinônimo de alta deliberatividade. Por outro lado, Ainsworth, Hardy e Harley (2005) também realizaram uma pesquisa comparativa entre dois fóruns. O primeiro, oficial, era mantido pelo Banco Mundial e tinha um objetivo de consulta online aos interessados em iniciativas da instituição. O segundo, criado por usuários do fórum oficial e que discordavam de seu excessivo controle, também tratava a respeito das políticas do banco mundial, mas sem contar com sua presença "oficial". Ou seja, apesar de ser mais autônomo do poder estatal, o segundo fórum alcançou menos respaldo pela ausência da presença institucional, o que segundo os autores foi uma forma da instituição demonstrar seu poder.

De tal modo, há indicadores quantitativos e indicadores qualitativos. Todos servirão de base 
para a análise da deliberatividade das mensagens. Apresentamos a Tabela 2, abaixo, que explicita nossa tipologia. Os indicadores numerados são aqueles que devem ser aplicados diretamente em cada mensagem analisada.

TABELA2 - CRITÉRIOS DE DELIBERATIVIDADE

\begin{tabular}{|c|c|}
\hline CRITÉRIO & SUBDIVISÕES \\
\hline Tematização e crítica racional & $\begin{array}{l}\text { (1) Reciprocidade } \\
\text { (2) Monológica } \\
\text { (3) Justificaçãão Externa } \\
\text { (4) Justificação Interna } \\
\text { (5) Posição }\end{array}$ \\
\hline Reflexividade & $\begin{array}{l}\text { (6) Persuasão } \\
\text { (7) Progresso } \\
\text { (8) Radicalização }\end{array}$ \\
\hline Ideal role taking & $\begin{array}{c}\text { (9) Respeito Implícito } \\
\text { (10) Respeito Explíito } \\
\text { (11) Sem Respeito: rude } \\
\text { (12) Sem Respeito: incivil } \\
\text { Continuidade: mensagens por dia }\end{array}$ \\
\hline Sinceridade & Excluída \\
\hline Inclusão e igualdade discursiva & $\begin{array}{l}\text { Pessoas com acesso à internet; } \\
\text { Número de postagem por pessoas }\end{array}$ \\
\hline $\begin{array}{l}\text { Autonomia do Estado e do poder } \\
\text { Econômico }\end{array}$ & $\begin{array}{l}\text { Análise qualitativa da atuação de instituições } \\
\text { que mantém ou financiam o fórum online }\end{array}$ \\
\hline
\end{tabular}

FONTE: o autor.

Os outros critérios a serem aplicados em cada mensagem são: "anônimo" (13), "identificado" (14), "nome" (15) e "data da postagem" (16). De tal maneira, toda mensagem será analisada pelos 16 critérios expostos. Obviamente, nenhuma mensagem conterá todos, pois alguns são excludentes e outros não surgirão por sua exigência normativa. Porém toda postagem será classificada pela data, pela identificação do participante (anônimo ou não) e pelo nome de usuário no local avaliado. Os outros indicadores serão avaliados qualitativamente em cada mensagem.

Finalmente, é importante notar que nenhum dos modelos que verificamos faz alusão aos diferentes indicadores de deliberatividade apresentarem níveis de importância distintos, ou seja, se alguns indicadores são mais vitais que outros para uma efetiva deliberação. A reflexividade, por exemplo, é uma atividade mais difícil e complexa de realizarse que a reciprocidade. De tal forma, uma das possibilidades seria atribuir diferentes pesos aos atributos da deliberatividade, logo o aparecimento de certos elementos seria preferível a outros. Entretanto, tal realização mostrou-se intrincada e pouco produtiva. Qual seriam os pesos atribuídos? A reflexividade é duas vezes mais importante que a reciprocidade? É apenas 30\% mais importante? A reflexividade e a justificação são igualmente importantes? Se não, qual a mais importante? Em que medida?

A teoria deliberativa é essencialmente muito abstrata para gerar tais números. Qualquer aplicação dessas medidas poderia levar a erros conceituais maiores que a análise distinta de cada indicador. Assim, acredita-se que o almejável seja gerar os diferentes resultados separadamente e depois realizar uma análise conjunta dos mesmos, na qual a própria perspectiva deliberacionista utilizada pode valorizar mais determinados operadores analíticos em detrimento de outros.

\section{ORÇAMENTO PARTICIPATIVO DIGITAL}

O Orçamento Participativo Digital foi lançado em 2006 pela prefeitura de Belo Horizonte. Nessa experiência, os eleitores da capital mineira foram capazes de escolher nove entre 36 obras préaprovadas exclusivamente pela internet. As obras vencedoras seriam realizadas pelo poder Executivo 
municipal. O sítio do programa (OPD, 2008) também apresentou ferramentas de participação online, como e-mail e fóruns de discussão. Ao final, o evento alcançou 172938 votos, o que representava $10 \%$ do eleitorado de Belo Horizonte.

Em 2008, o OPD foi realizado pela segunda vez. Nessa edição, a Prefeitura disponibilizou apenas cinco obras para a votação, sendo que apenas uma seria realizada. Além disso, todas as opções foram obras viárias de grande porte. Uma segunda diferenciação marcante do processo de 2008 foi a possibilidade de votar por um telefone gratuito. O processo alcançou 124320 votos, sendo 11483 pelo telefone.

Finalmente, importa destacar que as ferramentas participativas foram ampliadas. Além do fórum de discussão que foi reativado, foram implementadas dois novos instrumentos digitais. A primeira foi um chat (discussão em tempo real) que era aberto em determinadas épocas e que contou com a presença de agentes institucionais (secretários e coordenadores do OP presencial). A segunda foi a possibilidade de postar "recados" online. Em cada obra (1-5), havia uma opção de deixar um recado. Diferentemente do fórum, não era preciso cadastrar-se ou mesmo identificar-se para postar os comentários.

Por outro lado, essa ferramenta não ofereceu nenhuma sofisticação extra, geralmente encontrada em fóruns online, como a possibilidade de responder a uma mensagem específica (com seu conteúdo), de agrupar mensagens para responder ou mesmo utilizações de emoticons ${ }^{11}$, links, arquivos etc. Todas essas possibilidades ficaram restritas ao fórum online do OPD.

A ferramenta de postar comentários não apresentou qualquer divisão temática ou, mesmo, por tópicos. Todos os comentários, ao entrarem no sítio, eram dispostos em ordem temporal decrescente, ou seja, as postagens mais novas posicionavam-se na parte superior da discussão. Entretanto todas as postagens eram colocadas em um único grande tópico. Ou seja, pode-se dizer que foram cinco grandes fóruns online, um para cada obra do OPD.

Como a análise de deliberação online é essencialmente qualitativa, é preciso avaliar um corpus que seja significativo, mas também possível de ser analisado (BACHTIGER et alii, 2009). No total dos cinco pontos de conversação, foram geradas 1209 mensagens pelos participantes. Foram selecionadas 375 mensagens $^{12}$ que se encontravam nos fóruns das obras 4 e 5 , por serem as obras que alcançaram mais votos e foram escolhidas todas as mensagens que se referiram aos temas "trânsito lento e a obra atende à região" $(n=196)$ e "beneficiários da obra" $(n=179)^{13}$.

Para a avaliação da deliberatividade, recomenda-se a utilização de softwares específicos para análise qualitativa, que não apenas poupam tempo, mas permitem correlações e intercruzamentos que podem gerar resultados pertinentes. Obviamente, a utilização de fichas de análise (em programas de edição de textos comuns) também é um método funcional. Nessa pesquisa, foi utilizado o programa Atlas TI 5.5.

TABELA 3 - POSTAGENS POR OBRA DO OPD

\begin{tabular}{|l|c|c|}
\hline FÓRUM & OBRA PRÉ-SELECIONADA PARA VOTAÇÃO & NÚMERO DE POSTAGENS \\
\hline 1 & Av. José Cândido Silveira / Av. Andradas & 106 \\
2 & Av. Pedro I com Av. Portugal & 198 \\
3 & Av. Tereza Cristina com Anel Rodoviário & 69 \\
4 & Portal Sul / Belvedere & 306 \\
5 & Praça São Vicente com Anel Rodoviário & 544 \\
\hline
\end{tabular}

FONTE: o autor.

\footnotetext{
${ }^{11}$ Emoticons são um recurso comum na internet. São pequenas figuras na forma de expressões (tristeza, alegria, sarcasmo, expressões faciais etc.), que são geralmente utilizadas pelos internautas para que suas motivações sejam mais bem compreendidas no ambiente online.
}

\footnotetext{
12 Mensagens disponíveis em OPD (2008). Acesso em 2.mar.2011

13 Como as ferramentas de comentários não dispunham nenhuma organização por tema ou por tópico, realizou-se
} 
Após o fim das votações, tanto o fórum quanto o chat foram retirados do ar. As discussões realizadas também não foram disponibilizadas. A ferramenta de postar comentários deixou de ser habilitada, ou seja, era possível ver os comentários já realizados, mas não postar novas inserções.

\section{RESULTADOS}

Agora, demonstramos os resultados da aplicação do modelo nas mensagens selecionadas do fórum online do OPD. Devido à impossibilidade de identificar os usuários que postaram comentários e à impossibilidade de reunir um número significativos de eleitores aleatoriamente, optou-se por não se realizar um survey com os participantes. São apresentados os resultados simplificados ${ }^{14}$ em tabelas. Alguns dados, excessivamente extensos e complexos para nossos objetivos, foram intencionalmente suprimidos, como a "igualdade discursiva" e a "autonomia do Estado".

TABELA4 - ANÁLISE DAESTRUTURA DO FÓRUM

\begin{tabular}{|c|c|}
\hline $\begin{array}{l}\text { ESTRUTURA } \\
\text { COMUNICATIVA }\end{array}$ & RESULTADOS \\
\hline Identificação & Não era obrigatória, mas a maioria dos usuários se identificou. \\
\hline Abertura e liberdade & $\begin{array}{c}\text { Não houve direcionamento ou controle da Prefeitura das mensagens } \\
\text { sendo postadas. A ferramenta näo restringia ou mesmo } \\
\text { exigia qualquer tipo de cadastro. }\end{array}$ \\
\hline Agenda da discussão & $\begin{array}{l}\text { Obviamente, ao escolher obras viárias, a Prefeitura } \\
\text { agendou a discussão, entretanto não houve } \\
\text { qualquer intervenção institucional nas mensagens analisadas. }\end{array}$ \\
\hline Moderação & $\begin{array}{l}\text { Pré-moderado. As mensagens só eram liberadas } \\
\text { após avaliação, entretanto não houve qualquer manifestação } \\
\text { (mensagem) por parte dos moderadores. }\end{array}$ \\
\hline $\begin{array}{l}\text { Espaço público forte } \\
\text { ou fraco }\end{array}$ & $\begin{array}{l}\text { As ferramentas discursivas eram espaços fracos, pois não } \\
\text { eram pré-requisitos para a votação. Os participantes, entretanto, } \\
\text { usaram as ferramentas digitais para mobilização e convencimento } \\
\text { de outros cidadãos. O fato do mesmo sítio conter as ferramentas } \\
\text { de votação e discussão aparentemente tornou o espaço público forte. }\end{array}$ \\
\hline
\end{tabular}

FONTE: o autor.

TABELA5 - ANÁLISE DA CULTURA POLÍTICAE IDEOLOGIA

\begin{tabular}{|l|c|}
\hline \multicolumn{1}{|c|}{ CULTURA POLÍTICAE IDEOLOGIA } & RESULTADOS \\
\hline Diferenças culturais entre regiões & $\begin{array}{r}\text { As diferenças sócio-econômicas foram percebidas pelos } \\
\text { integrantes. A região cinco (vencedora) demonstrou } \\
\text { maior capacidade de mobilização. }\end{array}$ \\
$\begin{array}{l}\text { Tipo do ator político a hospedar } \\
\text { o debate }\end{array}$ & $\begin{array}{r}\text { Uma prefeitura liderada pelo Partido dos Trabalhadores (PT), } \\
\text { entretanto, a leitura das mensagens evidencia } \\
\text { que esse quesito pouco ou nada alterou os resultados. } \\
\text { Ideologia dos participantes }\end{array}$ \\
$\begin{array}{c}\text { Não pode ser apreendida pela não realização de uma survey } \\
\text { com os participantes. }\end{array}$ \\
$\begin{array}{c}\text { Trânsito, um assunto bastante próximo a todos os cidadãos. } \\
\text { Por afetar todas as camadas sociais, facilita que os diversos } \\
\text { atores envolvidos manifestem-se, inclusive apontando } \\
\text { Soluçöes práticas e baseadas em experiências pessoais. }\end{array}$ \\
\hline
\end{tabular}

FONTE: o autor.

uma divisão por temas, que buscou facilitar a avaliação do diálogo entre os participantes. Para o método completo de tal divisão, ver Sampaio (2010).
14 Os resultados foram simplificados por não ser o objetivo principal do texto. Para acesso aos resultados completos, ver Sampaio et alii (2010). 
TABELA 6 - DESIGN E CONTEÚDO

\begin{tabular}{|c|c|}
\hline CRITÉRIO & RESULTADOS \\
\hline Funcionalidade & $\begin{array}{c}\text { A navegação era simples e fácil, havendo links e abas } \\
\text { facilitadores. As ferramentas participativas foram bastante } \\
\text { simples, não dispondo de recursos avançados. A ferramenta } \\
\text { de postar comentários foi a menos sofisticada, não permitindo } \\
\text { a resposta direta a outros usuários, uso de citações, links e } \\
\text { multimídia. Ainda dispunha todas as postagens em bloco } \\
\text { sem divisão por temas ou tópicos e não apresentava } \\
\text { a opção de busca. }\end{array}$ \\
\hline Conteúdo & $\begin{array}{c}\text { Todas as obras apresentaram um conteúdo básico } \\
\text { para a participação, como custo, número de beneficiários, } \\
\text { localização, alterações no tráfego etc. Por outro lado, } \\
\text { não foram disponibilizadas informações mais completas } \\
\text { sobre tais obras, como relatórios, estudos sócio-econômicos } \\
\text { da região, características dos habitantes } \\
\text { e dados mais complexos no geral. }\end{array}$ \\
\hline
\end{tabular}

FONTE: o autor.

TABELA 7 - RESULTADOS DA DELIBERATIVIDADE ${ }^{15}$

\begin{tabular}{|l|c|c|c|c|c|}
\hline \multicolumn{1}{|c}{ CÓDIGOS } & $\begin{array}{c}\text { FÓRUM 4 } \\
\text { TEMA 1 }\end{array}$ & $\begin{array}{c}\text { FÓRUM 5 } \\
\text { TEMA 1 }\end{array}$ & $\begin{array}{c}\text { FÓRUM 4 } \\
\text { TEMA 2 }\end{array}$ & $\begin{array}{c}\text { FÓRUM 5 } \\
\text { TEMA 2 }\end{array}$ & TOTAL \\
\hline Número de mensagens & $50(100 \%)$ & $146(100 \%)$ & $100(100 \%)$ & $79(100 \%)$ & $375(100 \%)$ \\
Anônimo & $01(2 \%)$ & $01(0,7 \%)$ & $03(3 \%)$ & $01(1,27 \%)$ & $06(1,6 \%)$ \\
Identificado & $49(98 \%)$ & $145(99 \%)$ & $97(97 \%)$ & $78(99 \%)$ & $369(98,4 \%)$ \\
Dialógico & $6(12 \%)$ & $9(6,2 \%)$ & $86(86 \%)$ & $11(13,9 \%)$ & $112(29,87 \%)$ \\
Monológica & $44(88 \%)$ & $137(94 \%)$ & $14(14 \%)$ & $68(86 \%)$ & $266(70,93 \%)$ \\
Justificação externa & $20(40 \%)$ & $29(19,9 \%)$ & $75(75 \%)$ & $29(36,7 \%)$ & $153(40,8 \%)$ \\
Justificação interna & $6(12 \%)$ & $23(15,7 \%)$ & $8(8 \%)$ & $9(11,4 \%)$ & $46(12,26 \%)$ \\
Posição & $21(42 \%)$ & $74(50,7 \%)$ & $15(15 \%)$ & $41(51,9 \%)$ & $151(40,26 \%)$ \\
Persuasão & $1(2 \%)$ & $3(2 \%)$ & $5(5 \%)$ & $1(1,27 \%)$ & $10(2,6 \%)$ \\
Progresso & $5(5 \%)$ & $1(0,7 \%)$ & $55(55 \%)$ & $5(6,3 \%)$ & $66(17,6 \%)$ \\
Radicalização & $0(0 \%)$ & $0(0 \%)$ & $11(11 \%)$ & $0(0 \%)$ & $11(2,9 \%)$ \\
Respeito implícito & $13(26 \%)$ & $38(26 \%)$ & $25(25 \%)$ & $32(40,5 \%)$ & $108(28,8 \%)$ \\
Respeito explícito & $8(16 \%)$ & $25(17,1 \%)$ & $15(15 \%)$ & $8(10,1 \%)$ & $56(14,93 \%)$ \\
Sem respeito: rude & $1(2 \%)$ & $0(0 \%)$ & $22(22 \%)$ & $0(0 \%)$ & $23(6,1 \%)$ \\
Sem respeito: incivil & $0(0 \%)$ & $0(0 \%)$ & $0(0 \%)$ & $0(0 \%)$ & $0(0,0 \%)$ \\
\hline
\end{tabular}

FONTE: o autor.

Nosso objetivo não é discutir cada um dos resultados encontrados, mas tentar demonstrar que o modelo foi aplicado e que pode gerar resultados pertinentes, especialmente no cruzamento das

\footnotetext{
15 Resultados sendo considerados por coluna. Cada porcentagem equivale ao total de mensagens da coluna. A última coluna apresenta os resultados totais dos dois fóruns analisados.
}

diferentes análises.

Primeiramente, o fato do fórum não exigir cadastro ou identificação não implicou maior anonimato ou maior descomprometimento com a discussão, o que pode ser comprovado pelos altos níveis de justificação. Também não houve evidências de maior igualdade discursiva pela possibilidade do anonimato.

Depois, é possível perceber que os resultados de reciprocidade e reflexividade foram baixos no 
geral, porém significativos, dado o fato de ser uma ferramenta de postar comentários. Tal instrumento digital pode ter facilitado a participação por sua extrema simplicidade, mas torna-se um grande empecilho a qualquer tipo de discussão mais próxima de uma deliberação. Ela não permite a procura de palavras, a divisão de tópicos, a citação de outras mensagens, o envio de sons, imagens ou vídeos.

Se reciprocidade e reflexividade foram baixas, por outro lado, o nível de justificação por parte dos usuários foi bem acima do esperado e, interessantemente, a justificação externa foi superior à interna, contrariando as expectativas de que os participantes concentrassem-se no uso de testemunhos (SAMPAIO, 2010). Em outra análise de um fórum online tratando de trânsito (DANTAS \& SAMPAIO, 2010), houve resultados similares. Como nesse caso, acredita-se que seja um tema que concerne a todos. Se o fórum foi utilizado para mobilização e convencimento, provavelmente o uso de testemunhos teria pouco apelo, uma vez que todos são afetados pelos problemas do trânsito. Assim, é plausível afirmar que o alto uso de argumentos esteve ligado ao empenho dos cidadãos para convencerem outros eleitores sobre qual seria obra mais importante. Além disso, por ser algo muito próximo à realidade dos habitantes da cidade, o trânsito é um tema que praticamente todos habitantes conhecem bem, sendo, dessa forma, mais fácil e natural apresentar argumentos a seu respeito.

Finalmente, no que tange à escuta respeitosa, o fato de o fórum ser pré-moderado é capaz de explicar a baixa presença de mensagens rudes e a ausência de mensagens incivis, afinal tais mensagens, se existiram, podem nunca ter sido liberadas pelos moderadores. Por outro lado, considerando que houve grande liberdade e abertura para discussão e ausência do agente institucional, ele não explica a presença de altos valores de respeito implícito e explícito. Esses resultados, segundo nossa análise anterior (SAMPAIO, 2010), estão mais relacionados ao fato das pessoas terem utilizado o fórum como meio de mobilização e convencimento de outros eleitores e pelo tema, que sendo algo que afeta a todos, pode ter levado os usuários a respeitarem mais as causas alheias.

Logo, o modelo foi aplicado em praticamente sua totalidade e permitiu a extração de resultados conexos, mesmo sem a utilização de pesquisas com os participantes ${ }^{16}$. Apesar da ausência de tais dados impedirem conclusões definitivas, o cruzamento proposto certamente dá indicações interessantes sobre fatores e variáveis que incidiram na deliberação online.

Obviamente, o modelo precisa ser adaptado a cada situação. Em sua maioria, os arquétipos originais foram pensados para fóruns de discussão online. Em nosso caso, houve uma aplicação a uma ferramenta de postar comentários, o que exigiu mudanças pequenas. Uma aplicação a uma ferramenta discursiva muito díspar, como o Twitter, por exemplo, certamente exigirá modificações maiores. As hashtags ${ }^{17}$, por exemplo, poderão ser utilizadas como tópicos de conversa e os retweets como formas diretas de reciprocidade. Logo, acredita-se que o modelo possa ser aplicado a qualquer troca discursiva realizada na internet.

Estudos de deliberação nas mídias de massa tradicionais, especialmente a TV e jornais impressos também se utilizam de parâmetros similares (MAIA, 2008; WESSLER, 2008). O modelo apresentado neste artigo também pode ser aplicado a tais mídias, todavia demandará outras adaptações. Há, por exemplo, maiores dificuldades de afirmar quem está realizando o proferimento; haverá muita desigualdade no número de falas entre os atores presentes e será mais complexo avaliar se as mensagens estão efetivamente dialogando entre si. As características estruturais também devem ser adaptadas para o meio em questão. Para um impresso, por exemplo, conta a localização na página, imagens e o tamanho da matéria. Na TV, devem ser considerados os soundbites das falas, se é uma fala direta ou reproduzida por repórteres, imagens e duração das reportagens. Por outro lado, os nossos indicadores e suas subdivisões certamente permitirão uma avaliação mais completa das notícias e das falas dos atores envolvidos.

16 É importante notar que grande parte das pesquisas de deliberação online não realiza surveys ou pesquisas com os usuários, mas concentra-se nas mensagens postadas.

17 Ver Twitter (2012) para explicações do funcionamento da ferramenta. 
Com outros ajustes, inclusive pequenos, o modelo pode ser usado para análise de debates presenciais. Steenbergen et alii (2003) e Bachtiger et alii (2009) realizaram a aplicação de um modelo similar a discussões presenciais em parlamentos. Defende-se que o nosso modelo também possa ser aplicado a discussões offline, que tenham sido registradas pelo pesquisador. Acredita-se que, nesse caso, seja pertinente considerar questões relacionadas à fala, como o tom da voz (ironia, sinceridade, tristeza, alegria, seriedade etc.) e uso de expressões faciais ou ainda de gestos.

\section{CONCLUSÕES}

Apresentou-se um modelo de deliberação online que fosse amplo para a análise de conversações nos altos quesitos dos democratas deliberacionistas, mas também simples o suficiente para ser aplicado a diversas mídias e contextos.

O modelo sugerido é basicamente retirado de diversos outros arquétipos já testados e aplicados, mas busca exatamente valorizar os indicadores que se mostraram funcionais em estudos anteriores. Visando averiguar sua confiabilidade, o modelo foi aplicado a mensagens extraídas do fórum online do programa Orçamento Participativo Digital e demonstrou ser plausível e coerente.

Segundo a aplicação, a discussão apresentou bons valores de deliberatividade, especialmente no que tange à justificação das mensagens e ao respeito pelos outros usuários. Demonstrou-se que é possível inferir alguns dos resultados por meio de cruzamentos das diferentes avaliações, como os dados estruturais do fórum online com os resultados de deliberatividade. De tais intersecções, é possível inferir determinados resultados da deliberação e verificar os pontos fortes e fracos da discussão e das próprias ferramentas digitais.

Buscou-se, ainda, demonstrar que o modelo pode ser aplicado a diferentes ferramentas discursivas na internet com as devidas adaptações e que pode inclusive ser aplicada a outras mídias de massa ou mesmo a conversações presenciais. Apesar de cada meio exigir mudanças e adaptações, defende-se que os pré-requisitos básicos da teoria deliberativa, expressos em nosso modelo, serão sempre similares.

Especificamente, a deliberação online ainda é pouco visitada na pesquisa brasileira. De tal maneira, o presente modelo visa colaborar com a expansão de tal área, que tende a ampliar-se, considerando as diversas ferramentas interativas e discursivas disponíveis online e a elevação constante no uso da internet por instituições políticas e pelos próprios representantes políticos. Os resultados de tais estudos podem ser considerados na criação (ou revisão) de programas deliberativos institucionais ou, simplesmente, fóruns deliberativos ${ }^{18}$, que possam não apenas abarcar discussão democrática entre cidadãos, mas que a facilitem e a incentivem. Sendo, esse, um dos possíveis caminhos para uma democracia mais deliberativa.

18 Além do OPD, outros casos proeminentes começam a surgir, como a utilização da internet no OP presencial de Recife e o caso da consulta estadual realizada no Rio Grande do Sul.

Rafael Cardoso Sampaio (cardososampaio@yahoo.com.br) é Doutorando em Comunicação e Cultura Contemporâneas pela Universidade Federal da Bahia (UFBA).

\section{REFERÊNCIAS BIBLIOGRÁFICAS}

AINSWORTH, S.; HARDY, C. \& HARLEY, B.

2005. Online Consultation: E-Democracy and E-Resistance in the Case of the Development Gateway. Management Communication Quarterly, Thousand Oaks, v. 19, n. 1, p. 120145, Aug.

ALVES, N. T. T. A conversação cívica sobre a questão do aborto em redes sociais na internet. São Paulo. Dissertação (Mestrado em
Comunicação) Faculdade Cásper Líbero.

BACHTIGER, A.; SHIKANO, S.; PEDRINI, S.; \& RYSER, M. 2009. Measuring Deliberation 2.0: Standards, Discourse Types, and Sequenzialization. Trabalho apresentado na $5^{\text {a }}$ ECPR General Conference, realizada em Potsdam, Alemanha, de 10 a 12 de setembro. Digit. Disponível em: http://ash.harvard.edu/extension/ ash/docs/baechtiger.pdf. Acesso em: 16. maio. 2012. 
BRAGATTO, R. C. 2008. Política e internet: oportunidades de participação democrática nos portais dos executivos nacionais dos seis maiores países sul-americanos. Curitiba. Dissertação (Mestrado em Sociologia e Política). Universidade Federal do Paraná.

COHEN, J. \& FUNG, A. 2004. Radical Democracy. Swiss Journal of Political Science, London, v. 10, n. 4, p. 23-34, Winter. Disponível em: http://www.archonfung.net/papers/ Cohen_Fung_Debate_SPSR2004.pdf. Acesso em: 17.maio.2012.

COLEMAN, S. \& GØTZE, J. 2001. Bowling Together: Online Public Engagement in Policy Deliberation. London: Hansard.

DAHLBERG, L. 2001. Extending the Public Sphere through Cyberspace: The Case of Minnesota E-Democracy. First Monday, London, v. 6, n. 3, p. 147-163. Disponível em: http://firstmonday.org/htbin/cgiwrap/bin/ojs/ index.php/fm/article/view/838/747. Acesso em: 16.maio. 2012 .

2004a. Net-Public Sphere Research: Beyond the "First Phase". The Public, v. 11, n. 1, p. 27-44. Disponível em: http://javnostthepublic.org/article/pdf/2004/1/2/. Acesso em: 16.maio.2012.

2004b. The Habermasian Public Sphere: A Specification of the Idealized Conditions of Democratic Communication. Studies in Social and Political Thought, Sussex, n. 10, p. 118, Aug. Disponível em: http:// www.sussex.ac.uk/cspt/documents/101a.pdf. Acesso em: 16.maio.2012.

DANTAS, M. \& SAMPAIO, R. C. 2010. Fóruns online e deliberação: conversações restritas ou participação democrática? Trabalho apresentado no $19^{\circ}$ Encontro da Associação Nacional dos Programas de Pós-Graduação em Comunicação, realizado no Rio de Janeiro de 8 a 11 de junho. Digit.

DAVIS, R. 2005. Politics Online: Blogs, Chatrooms and Discussion Groups in American Democracy. London: Routledge.

DRYZEK, J. 2004. Legitimidade e economia na democracia deliberativa. In: COELHO, V. S. P. \& NOBRE, M. (orgs.). Participação e deliberação: teoria democrática e experiências institucionais no Brasil contemporâneo. São Paulo: ed. 34.

FERBER, P.; FOLTZ, F. \& PUGLIESE, R. 2007. Cyberdemocracy and Online Politics: A New Model of Interactivity. Bulletin of Science, Technology and Society, Thousand Oaks, v. 27, n. 5, p. 391-400, Oct.

FUNG, A. 2004. Receitas para esferas públicas: oito desenhos institucionais e suas conseqüências. In: COELHO, V. S. P. \& NOBRE, M. (orgs.). Participação e deliberação: teoria democrática e experiências institucionais no Brasil contemporâneo. São Paulo: ed. 34.

GASTIL, J. 2000. Is Face-to-Face Citizen Deliberation a Luxury or a Necessity? Political Communication, London, v. 17, n. 4, p. $357-$ 361.

GOMES, W. 2002. Internet, censura e liberdade. In: PAIVA, R. (org.). Ética, cidadania e imprensa. Rio de Janeiro: Mauad.

GRAHAM, T. \& WITSCHGE, T. 2003. In Search of Online Deliberation: Towards a New Method for Examining the Quality of Online Discussions. Communications, Berlin, v. 28, n. 2, p. 173-204.

GRÖNLUND, Â. 2003. Emerging Electronic Infrastructures: Exploring Democratic Components. Social Science Computer Review, Thousand Oaks, v. 21, n. 1, p. 55-72, Spring.

GUTMANN, A. \& THOMPSON, D. 2007. O que significa democracia deliberativa. Revista Brasileira de Estudos Constitucionais, Belo Horizonte, v. 1, n. 1, p. 17-78, jan.-mar. Disponível em: http://www.upenn.edu/president/ images/president/pdfs/significa-democracia2007.pdf. Acesso em: 16.maio.2012.

HABERMAS, J. 1984. Mudança estrutural da esfera pública. Rio de Janeiro: Tempo Brasileiro.

1997. Direito e democracia: entre facticidade e validade. V. 2. Rio de Janeiro: Tempo Brasileiro.

HAMLETT, P. 2002. Adapting the Internet to Citizen Deliberations: Lessons Learned. Trabalho apresentado no International Symposium on Technology and Society (ISTAS'02), realizado em Raleigh, Estados Unidos, de 6 a 8 de junho. Digit. 
IASULAITIS, S. 2011. As possibilidades da ciberdemocracia: as modalidades de participação política em websites eleitorais. Anais do XI Congresso Luso Afro Brasileiro de Ciências Sociais, Salvador, agosto de 2011. Digit.

JANKOWSKI, N. \& VAN OS, R. 2004. Internetbased Political Discourse: A Case Study of Electronic Democracy in Hoogeveen. In: SHANE, P. M. (ed.). Democracy Online: The Prospects for Political Renewal through the Internet. New York: Routledge.

JENSEN, J. L. 2003. Public Spheres on the Internet: Anarchic or Government-Sponsored: A Comparison. Scandinavian Political Studies, Hoboken, v. 26, n. 4, p. 349-374, Dec. Disponível em: http://www.netdemocracy.dk/ Netdemocracy/Articles/Maastricht-artikel.pdf. Acesso em: 16.maio.2012.

JANSSEN, D. \& KIES, R. 2005. Online Forums and Deliberative Democracy. Acta Politica, Basingstoke, n. 40, p. 317-335. Disponível em: http://edemocracycentre.ch/files/onlineforums. pdf. Acesso em: 16.maio.2012.

LAZER, D.; NEBLO, M. \& ESTERLING, K. 2012. The Internet and the Madisonian Cycle: Possibilities and Prospects for Consultative Representation. In: COLEMAN, S. SHANE, P. (eds.). Connecting Democracy: Online consultation and the flow of Political Communication. Cambridge: MIT.

MAIA, R. C. M. (org.) 2008. Mídia e deliberação. Rio de Janeiro: Fundação Getúlio Vargas.

MALVA, R. B. 2011. O papel da cooperação humana no processo de deliberação online. Anais do $1^{\circ}$ Congresso Mundial de Comunicação Ibero-Americana, São Paulo, agosto.

MARQUES, A. C. S. 2010. A deliberação online como uma das dimensões políticas da comunicação mediada por computador: reflexões teórico-metodológicas. Trabalho apresentado no $33^{\circ}$ Congresso Brasileiro de Ciências da Comunicação (Intercom), realizado em Caxias do Sul de 2 a 6 de setembro. Digit. Disponível em: http://www.intercom.org.br/papers/nacionais/2010/resumos/R5-3056-1.pdf. Acesso em: 16.maio.2012.
MARQUES, F. P. J. A. \& MIOLA, E. 2007. Internet e parlamento: um estudo dos mecanismos de participação oferecidos pelo poder Legislativo através de ferramentas online. ECompós, Brasília, v. 9, p. 2-20, ago. Disponível em: http://www.repositorio.ufc.br:8080/ri/ bitstream/123456789/641/1/2007_art_\% $20 \mathrm{fpjamarques}$ _ranppgc.pdf. Acesso em: 16.maio.2012.

MENDONÇA, R. F. \& PEREIRA, M. A. A. 2011. Democracia digital e deliberação online: um estudo de caso sobre o VotenaWeb. Anais do IV Congresso Latino Americano de Opinião Pública da WAPOR, Belo Horizonte, maio.

MIN, S. 2007. Online vs. Face-to-Face Deliberation: Effects on Civic Engagement. Journal of Computer-Mediated Communication, Bloomington, v. 12, n. 4, p. 1369-1387. Disponível em: http://jcmc.indiana.edu/vol12/ issue $4 / \mathrm{min} . h \mathrm{tml}$. Acesso em: 16.maio.2012.

MIOLA, E. 2009. A deliberação online em ambientes institucionais. Um estudo do fórum de discussão do portal da Câmara dos Deputados. Contemporânea, Salvador, v. 7, n. 2, p. 1-24. Disponível em: http://www.portalseer. ufba.br/index.php/contemporaneaposcom/ article/download/3640/2871 Acesso em: 16.maio. 2012.

MITRA, A. 2001. Marginal Voices in Cyberspace. New Media \& Society, Thousand Oaks, v. 3, n. 1, p. 29-48, Mar.

MONNOYER-SMITH, L. 2012. The Technological Dimension of Deliberation: A Comparison between Online and Offline Participation. In: COLEMAN, S.; SHANE, P. (eds.). Connecting Democracy: Online Consultation and the Flow of Political Communication. Cambridge: MIT.

NOVECK, B. S. 2003. Designing Deliberative Democracy in Cyberspace: The Role of the Cyber-Lawyer. Journal of Science and Technology Law, Boston, v. 9, n. 1, p. 1-91. Disponível em: http://agoraproject.eu/papers/ Designing\%20 deliberative $\% 20$ democracy $\% 20$ in $\% 20$ cyberspace.pdf. Acesso em: 16.maio.2012.

PAPACHARISSI, Z. 2004. Democracy Online: Civility, Politeness, and the Democratic 
Potential of Online Political Discussion Groups. New Media \& Society, Thousand Oaks, v. 6, n. 2, p. 259-283, Apr.

SALTER, L. 2004. Structure and Forms of Use. A Contribution to Understanding the "Effects" of the Internet on Deliberative Democracy. Information, Communication \& Society, London, v. 7, n. 2, p. 185-206. Disponível em: http://www.academia.edu/attachments/ 5612368/download file. Acesso em: 16.maio.2012.

SAMPAIO, R. C. 2010. Participação e deliberação na internet: um estudo de caso do Orçamento Participativo Digital de Belo Horizonte. 2010. Belo Horizonte. Dissertação (Mestrado em Comunicação Social). Universidade Federal de Minas Gerais.

SAMPAIO, R. C. \& BARROS, S. A. R. 2010. Deliberação no jornalismo online: um estudo dos comentários do Folha.com. Intexto, Porto Alegre, v. 2, n. 23, p. 183-202, jul.-dez. Disponível em: http://seer.ufrgs.br/intexto/ article/view/16449/10518. Acesso em: 16.maio. 2012.

SAMPAIO, R. C.; MAIA, R. C. M. \& MARQUES, F. P. J. A. 2010. Participação e deliberação na internet: um estudo de caso do Orçamento Participativo Digital de Belo Horizonte. Opinião Pública, Campinas, v. 16, n. 2, p.446477, nov. Disponível em: http://www.scielo.br/ pdf/op/v16n2/a07v16n2.pdf. Acesso em: 16.maio.2012.

SANDERS, L. M. 1997. Against Deliberation. Political Theory, Thousand Oaks, v. 25, n. 3, p. 1-17, June. Disponível em: http:// faculty.virginia.edu/1sanders/SB617_01.pdf. Acesso em: 16.maio.2012.

SILVA, S. P.; AZEVEDO, D. P.; MORAIS, K. S.; PINTO, D. A. \& SILVA, S. M. 2009. Publicidade, accountability e participação nos parlamentos online da América Latina: estu- dos sobre seis países. Trabalho apresentado no $1^{\circ}$ Seminário Nacional de Sociologia e Política, realizado em Curitiba de 9 a 11 de setembro. Digit. Disponível em: http:// www.humanas.ufpr.br/site/evento/Sociologia Politica/GTs-ONLINE/GT3/EixoII/publicidade-accontability-Katia-Morais.pdf. Acesso em: 16.maio.2012.

STEENBERGEN, M. R.; BÄCHTIGER, A.; SPÖRNDLI, M. \& STEIER, J. 2003. Measuring Political Deliberation: A Discourse Quality Index. Comparative European Politics, Basingstoke, v. 1, n. 1, p. 21-48, Mar. Disponível em: http://www.poli-sci.utah.edu/ $\sim$ burbank/steenbergen2003.pdf. Acesso em: 16.maio.2012.

VITA, A. 2004. Democracia deliberativa ou igualdade eqüitativa de oportunidades? In: COELHO, V. S. P. \& NOBRE, M. (orgs.). Participação e deliberação: teoria democrática e experiências institucionais no Brasil contemporâneo. São Paulo: ed. 34.

VITALE, D. 2006. Between Deliberative and Participatory Democracy: A Contribution on Habermas. Philosophy Social Criticism, Thousand Oaks, v. 32, n. 6, 739-766, Sept.

WARREN, M. E. 2007. Institutionalizing Deliberative Democracy. In: ROSENBERG, S. W. (ed.). Deliberation, Participation and Democracy: Can the People Govern? New York: Palgrave Macmillan.

WESSLER, H. 2008. Investigating Deliberativeness Comparatively. Political Communication, London, v. 25, n. 1, p. 1-22.

WILHELM, A. 2000. Democracy in the Digital Age: Challenges to Political Life in Cyberspace. New York: Routledge.

WRIGHT, S. \& STREET, J. 2007. Democracy, Deliberation and Design: The Case of Online Discussion Forums. New Media \& Society, Thousand Oaks, n. 9, p. 849-869.

\section{OUTRAS FONTES}

CETIC. 2012. Sitio de internet do Centro de Estudos sobre as Tecnologicas da Informação e da Comunicação. Disponível em: http:// www.cetic.br/. Acesso em: 16.maio.2012.

OPD. 2008. Sitio do Orçamento Participativo
Digital. Disponível em: http://opdigital. pbh.gov.br/. Acesso em: 16.maio.2012.

TWITTER. 2012. Seção de "ajuda” do sítio do Twitter. Disponível em: http://twitter.com/help/ start. Acesso em: 16.maio.2012. 


\section{HOW DELIBERATIVE ARE INTERNET DISCUSSIONS? A MODEL FOR UNDERSTANDING ONLINE DELIBERATION}

\section{Rafael Cardoso Sampaio}

This article presents a series of indicators for analysis of internet conversations through the prism of theories of deliberative democracy. The model we propose is made up of an examination of the structure of an on line forum, the evaluation of actors involved in the debate, reflections on the context of discussion and analysis of the "deliberativeness" of the messages themselves, based on Habermas' principles for the public sphere. Finally, the described model of on line deliberation is applied to messages taken from the on line forum, Digital Participatory Budgeting, from Belo Horizonte. Application of the model indicates that the discussion brought positive deliberative results, 
especially with regard to message justification and respect for other users. Finally, we argue that the model can be widely applied to on line discussions in different platforms, or - with certain adaptations, to other discursive means, such as mass media or live parliamentary debate.

KEYWORDS: Civil Participation; Deliberative Democracy; Public Sphere; Online Deliberation. 
À QUEL POINT LES DISCUSSIONS SUR LE RÉSEAU SONT DÉLIBÉRATIVES ? UN MODĖLE D'APPRÉHENSION DE LA DELIBÉRATION EN LIGNE

\section{Rafael Cardoso Sampaio}

Cet article présente un ensemble d'indicateurs pour l'analyse de conversations réalisées sur internet à la lumière des théories de démocratie délibérative. Le modèle proposé est composé d'un examen de la structure d'un forum en ligne, par l'évaluation des acteurs impliqués dans le débat, la réflexion du contexte de la discussion et par l'analyse de la « délibérativité » des messages entre eux, où l'on prend les principes de Habermas pour la sphére publique. Finalement, le modèle décrit de la délibération en ligne est apliqué à des messages extraits du forum en ligne du « Budget Participatif Numérique » de Belo Horizonte. L'application du modèle indique que la discussion a présenté des bons résultats de " délibérativité », spécialement par rapport à la justification des messages et au respect par les autres internautes. Enfin, on montre que le modèle peut être largement appliqué dans des discussions en ligne sur des différentes plateformes ou, avec certaines adaptations, dans d'autres milieux discursifs, comme des médias massives ou des parlements présentiels.

MOTS-CLÉS: participation civile; démocratie délibérative; sphère publique; délibération en ligne. 